\title{
Book review of Van der Graaf, S. (2018). ComMODify: User creativity at the intersection of commerce and community. London: Palgrave Macmillan.
}

Ana Jorge*

* Universidade Católica Portuguesa, Portugal

This book by Shenja Van der Graaf offers a detailed study to investigate user participation in a platform of the software industry, crucially a "firm-hosted platform that thrives on user participation and creativity" ( $p$. 16). The author, currently a Senior Researcher at imec-SMIT of Vrije Universiteit in Brussels, seeks to address the gap in existing scholarship on user-participation which "has tended to be based frequently on intuitive claims about user participation" (p. 9). The research focuses on modding, an abbreviation for the practice of modifying a game by a developer. In looking at Second Life as the main case, this work "tells a story of content creation, connectivity and commodification between the developer firm and user communities indicative of tensions such as those about exploitation and privacy we are currently facing online associated with the transition from user-based to market-based platforms like Facebook" (p. 3).

Van der Graaf engages with literature on participation - from Jenkins to Bruns and Van Dijck - which has been established as a relevant framework to understand user creative practices, as she attempts to focus on the interplay between structure and agency to make sense of the "changing social and economic arrangements between the more traditional division of labour and between production and consumption" (p. 30). It also draws on literature on cultural production and labour in the 'talent-led economy', where work and play appear increasingly blurred as individuals are subject to precariousness and exploitation, but sustain personal motivations to push innovation or simply engage in creation. Other pillars of ComMODify are the conceptual framework on communities, particularly communities of practice, to grasp their role in the production of knowledge; and innovation theories. The work contributes to the debate on the complexities of the current trend of platformization of the internet, turning to authors such as Gillespie, Bucher and Postigo. It looks at user participation "as a dynamic process evoked in a context and particular organization of the roles of different groups of contributors (including the developer firm and individuals)" (p. 49), where a socio-economic model that invites users to create is underpinned by emerging norms and values.

The book explores in depth the structures and norms for participation in commercial platform, and the values attributed to creativity, or creative labour, through the concepts of 'design capabilities', 'design space' and 'learning by design'. Second Life users take part in a system of distributed design and decision-making where they are passionate about collaborating, or motivated by social, topical or technical aspects. Van der Graaf builds an interesting typology of users according to participation and communication on Second Life (pp. 73-74), and finds that "most users are less motivated by monetary rewards" and rather by "social interactions, creativity and the innovation potential" (p. 84). The study looks at the level of the design space of Linden Lab and the ways in which users view ownership differently, and how norms and attitudes evolve in the dynamic relationship between users and the developer firm, amidst growing professionalization of user creativity. It is this relational approach that leads Van der Graaf to understand mod development as a 
learning dynamic, where interactions between the community contribute to the generation of knowledge, which ultimately "may particularly benefit the firm" (p. 114).

The book thus critically analyses the relationship between socioeconomic organisations in the "dialectics of community and market" (p. 143), between emancipation and collaboration. This perspective runs counter the rhetoric of user-generated content as well as its criticism, arguing for attention to be paid to "a complex interdependent dynamic encompassing both commercial and non-commercial interests between the developer firm and the user base" (p. 150), "simultaneously structured and emergent, top-down and bottomup, centralized and dispersed, commercial and non-commercial" (p. 166).

This is a timely book, offering an empirically based and theoretically rich, critical approach to the role of platform development and user participation in the current ecosystem where platforms occupy a central role in the socioeconomic structure of media and communications, and where algorithms increasingly govern the organization of content. Crucially, Van der Graaf ends by calling attention to the need to reexamine privacy regulation as well as media literacy and education, as accounting for the capabilities people need to access the digital environment. In other words, how can we balance commodification and public value? It is therefore a valuable contribution for those, from media and sociology as well as economy, interested in discussing the implications of user involvement in platforms such as Facebook or other social media, or the emergent integration of connectivity in objects known as Internet of Things. 